null • Business of Knowing

\title{
Now is the Time to Fund Open Infrastructures
}

Peter Kraker ${ }^{1}$

${ }^{1}$ Open Knowledge Maps

Published on: Aug 16, 2021

DOI: $10.21428 / 6 \mathrm{ffd} 8432 . \mathrm{ald} 2856 \mathrm{~b}$

License: Creative Commons Attribution 4.0 International License (CC-BY 4.0) 
Recently, open infrastructures have gotten a lot of attention. This primarily comes down to two reasons: current events and economics.

Firstly, open infrastructures have proven to be essential for COVID-19 research. Open data portals and open source software power research efforts in data collection, analysis, and modeling efforts. Preprint servers and open discovery platforms have been at the heart of a rapid exchange of the knowledge benefitted in the process. The impact of openness on coronavirus research was widely recognized, prompting organisations such as the OECD to include open science in their key policy responses to the COVID-19 pandemic []].

The second reason that open infrastructures are in the spotlight is that they are seen as an antidote to the increased market concentration observed in the scholarly communication space. In recent years, large commercial companies such as RELX (Elsevier), SpringerNature, and Clarivate have formed through mergers and acquisitions. They bring together proprietary software spanning the whole research life-cycle. They are looking to control content, software, and research metrics, thus locking research organizations and funders into their software. In the process, they are using tried and tested methods from the giants of the tech world such as Facebook, Microsoft, and Google, including the surveillance capitalism that comes with it (see [2] []ㅡ for more context).

Open infrastructures, on the other hand, are often scholar-led and run by non-profit organisations, making them mission-driven instead of profit-driven. Data and content created by and in the systems are published under an open license and made available following open standards. Ideally, they are based on open source software. This makes migration from one system to another much easier and avoids lock-in effects. Another important distinction is that open infrastructures provide appropriate opportunities for community input and involvement in decision-making and governance processes. These qualities make open infrastructures hard to buy out. It is no coincidence that the draft for the forthcoming UNESCO Open Science declaration [4] calls for open science infrastructure to be not-for-profit and to be as open as possible.

Across the space, funders, policy makers, and research organisations are coming to the conclusion that current transformation models towards open science are broken, most notably the big deals with large commercial publishers, and that open infrastructure is at the heart of the solution. One clear indication of organisational support of open infrastructure is the \$3.4 million (USD) grant from Arcadia to Invest in 
Open Infrastructure (IOI), an initiative dedicated to improving funding and resourcing for open technologies and systems supporting research and scholarship.

In the process, improving the financial situation of open infrastructure has emerged as a key issue. Open infrastructures are among the most important actors in the system, but they are also among the most vulnerable. Recent landscape analyses by IOI [ $\underline{5}$ ] and SCOSS [] ] concluded that some of the most heavily used services make ends meet with a tiny core team of two to five people. The same study found that half rely on volunteers to provide basic services, and the majority of infrastructures would close within just six months without continued research grants, which are meant as a jumping off point, not a long-term solution.

There simply isn't enough funding for maintenance and further development of open infrastructures.

And while open infrastructures have shined in the coronavirus crisis, they are struggling with the economic fallout from the pandemic as research organisations are forwarding budget cuts and uncertain situations. This is exemplified by the number of applications that even a small funding opportunity such as the JROST Rapid Response Fund [7], meant to mitigate some of the problems that the pandemic has caused for nonprofit infrastructures, receive. More than 50 organisations applied for one of eight awards of a maximum USD 10,000 each.

It is clear: the ecosystem of non-profit open infrastructures is at breaking point.

On the other end of the spectrum, the large commercial companies are flush with cash, not least from reaping the rewards from their publishing oligopoly. They use these resources to build their proprietary one-stop-shop platforms. Once these systems are in place, they will be almost impossible to replace.

As long as there is funding, people will build infrastructures. For example, people are still developing web search engines. And in some niche markets, they may be successful, see for example DuckDuckGo. But none of them has a chance of rivaling Google, which has a market share of $92 \%$ according to statcounter. It's not for a lack of innovation that they cannot compete - Google's sheer market dominance ensures that they will be either bought up, relegated to a niche, or driven out of the market. The same threatens to happen with the scholarly infrastructure.

It is therefore a race against time. And time is not on the side of the advocates of open science. 
The lack of funding for open infrastructures is a systemic problem. As such, it is tempting to think that in order to solve this problem, we just need to find one largescale mechanism to fix it at the same scale that the big corporations act upon. For example, a portion of each research grant should go towards open infrastructures used for the execution of that research. Or that a certain share of each university library budget should go there. Or that funders pool money that will be distributed among open infrastructures depending on their use.

Now I am not against these large-scale solutions. I think that they will be an important piece of the puzzle. However, it is important to understand that there is not a single sweeping solution to this issue, as funding structures, legal frameworks, and organizational requirements vary significantly throughout the world. As a result, any large-scale sustainable funding mechanism for OIs, if and when it gets implemented, will still be limited geographically. Furthermore, it will take many years for them to be conceptualized and implemented. Compared to other organizations, research performing institutions and funders move at a glacial pace and budgets and frameworks are often set for years to come.

That's too late, at least for the current iteration of open infrastructures. While they are fighting for survival, the proprietary platforms will be kept in place and with every passing year, they will be harder to replace.

This means two things. First, there is no time for hesitation any more when it comes to funding open infrastructures. Second, we cannot lean on anyone to solve this issue magically for us. Everyone who wants an open scholarly infrastructure needs to become active now.

Take SCOSS as an example. SCOSS is a coalition of organizations looking to sustain not-for-profit open infrastructure via funding recommendations. SCOSS started by identifying two infrastructures that were deemed essential to the community and then it went out to find funding for them. They evaluated this approach with each iteration and applied the insight from these reviews to the next application and funding processes (see []] for an example of such an evaluation).

By design, SCOSS is not perfect and it can only take on a small share of OIs in need of funding. Over two rounds of open calls for expressions of interest, 50 infrastructures applied for support. Of those, roughly $10 \%$ will be taken on board (the latest round of applications is still ongoing). But SCOSS made it a priority to act. In the process, they have already helped one organisation, the Directory of Open Access Journals (DOAJ), 
to reach its funding goal, and others will follow. This has made SCOSS one of the most innovative initiatives in open infrastructure funding.

We need more SCOSS-like experimentation. We need initiatives with short iterations of conceptualization and execution, a sort of trial-and-error mentality as we navigate this complex issue. We need research organisations and libraries to create budget lines for open infrastructures. We need funders to start supporting the maintenance of open infrastructures like the eLife Innovation Initiative or the Chan Zuckerberg Foundation.

The good thing is, almost everyone can get started on this issue. As a researcher, suggest to your institution that they support the open infrastructures that you find particularly useful. As a library, start supporting some infrastructures that you see as particularly beneficial for your institution and the larger open infrastructure ecosystem. As a funder, experiment with funding schemes that target open infrastructure sustainability. Whatever you do, make sure that funding is being redirected to the open infrastructure in the process.

If the money keeps going to closed systems, these will prevail.

Given proper funding, open infrastructures could finally unleash their full innovation potential. The scales could start to dip in favour of open infrastructures, a sort of Wikipedia-effect where open infrastructure becomes the norm. We have seen encouraging examples where this has already happened, such as preprint servers and the non-profit open access infrastructure in Latin America [ㅁ] [10].

It goes without saying that this scenario is far from given.

Now is the time to fund open alternatives to closed and proprietary infrastructures. Otherwise, we will soon be left with no alternatives. 


\section{Citations}

1. OECD. "Why Open Science Is Critical to Combatting COVID-19." OECD Policy Responses to Coronavirus (COVID-19), 12 May 2020.

http://www.oecd.org/coronavirus/policy-responses/why-openscience-is-critical-to-combatting-covid-19-cd6ab2f9/ (12.08.2021). 2. Erin Rose Glass. "Open access in an age of surveillance technology". http://www.erinroseglass.com/open-access-in-an-age-of-surveillance-technology $/$ $(12.08 .2021) \subseteq$

3. Brembs, B., Förstner, K., Kraker, P., Lauer, G., Müller-Birn, C., Schönbrodt, F., \& Siems, R. (2020). Auf einmal Laborratte. Frankfurter Allgemeine Zeitung. https://doi.org/10.5281/ZENODO.4317253

4. UNESCO. "Draft text of the UNESCO Recommendation on Open Science." Intergovernmental Meeting of Experts (Category III) related to a Draft UNESCO Recommendation on Open Science, 6-7 and 10-12 May 2021. https://unesdoc.unesco.org/ark:/48223/pf0000376893? posInSet=7\&queryId=64f6c09b-9508-4258-82a1-e195d9d38368 (12.08.2021). ㅌ 5. Thaney, Kaitlin. "The Open Scholarship Ecosystem Faces Collapse; It's Also Our Best Hope for a More Resilient Future." Impact of Social Sciences (blog), June 19, 2020. https://blogs.lse.ac.uk/impactofsocialsciences/ 2020/06/19/theopen-scholarship-ecosystem-faces-collapse-its-also-our-best-hope-for-a-more-resilientfuture/ (11 August 2021). 6. Ficarra, V., Fosci, M., Chiarelli, A., Kramer, B., \& Proudman, V. (2020). Scoping the Open Science Infrastructure Landscape in Europe. Zenodo. https://doi.org/10.5281/ZENODO.4153809

7. https://investinopen.org/blog/jost-rapid-response-fund/ 8. SCOSS. "An evaluation of the SCOSS Pilot Project." SCOSS Progress Report, March 2019. file://C:/Users/pkraker/AppData/Local/Temp/theSCOSSProgressReport_March2019.p df/ (12.08.2021).

9. https://www.redalyc.org $/ e$ 
10. http://amelica.org. 